\title{
Using the Multi-Attribute Utility Model to Better Understand Fruit and Vegetable Intake among College Students
}

\author{
Anna Stiles Hanlon ${ }^{1}$, Jie Wu Weiss ${ }^{2}$, Shari McMahan ${ }^{2}$ and Emily Cheng ${ }^{2}$ \\ ${ }^{1}$ Orange Coast College \\ ${ }^{2}$ California State University, Fullerton
}

\begin{abstract}
This study examined the association between parameters of the decision-making processes that are described in the Multi-Attribute Utility (MAU) model and actual food choices (fruit and vegetable consumption) among undergraduate students. Four hundred and six undergraduates from a large, public university in Southern California completed a pencil-and-paper questionnaire for the parameters of MAU, which consist of the perceived value, perceived likelihood, and momentary salience for each anticipated consequence of eating a healthy diet. Fruit and vegetable intake was collected daily using an online food intake log. Linear regression analysis revealed that MAU total scores were a significant predictor of fruit plus vegetable consumption $(\mathrm{p}=.000)$. T-test results indicated that high fruit plus vegetable eaters and low fruit plus vegetable eaters were significantly different from each other on individual parameter scores of the MAU model (range, $\mathrm{p}=.032$ to $\mathrm{p}=.000$ ). Conclusions: This study suggest that the MAU model may predict eating behaviors and provides support for further investigation; the MAU framework may help identify the factors that have greatest influence college students' nutrition decision making processes, and can aid in the development of interventions that address target consequences that have high utility scores in the target population.
\end{abstract}

(C) 2012 Californian Journal of Health Promotion. All rights reserved.

Keywords: decision making, Multi-Attribute Utility model (MAU), food choice, fruits and vegetables, college students

\section{Introduction}

The prevalence of overweight and obese individuals has reached epidemic proportions in the United States; approximately $67.1 \%$ of men and $55.8 \%$ of women ages $20-39$ years are classified as overweight (BMI > 25), with $33.2 \%$ of these men and $31.9 \%$ of these women being classified as obese (BMI > 30) (Flegal, Carrol, Kit, \& Ogden, 2012). The National College Health Assessment II found that $31.9 \%$ of the 83,070 college students surveyed were overweight, with $10 \%$ of the students classified as obese (American College Health Association, 2009). One of the primary contributing factors in the development of becoming overweight or obese is poor food choices. The current trend of frequently consuming fast food, sugar sweetened beverages and other calorie-dense foods increases overall daily caloric intake and decreases daily consumption of fruits and vegetables (Brownell, 2004). This trend is problematic because fruit and vegetable consumption reduces obesity risk and aids in weight loss and maintenance (Center for Disease Control and Prevention, 2005). Long-term outcomes of fruit and vegetable consumption include protection against heart disease, diabetes, cancer and other chronic diseases (U.S. Department of Health and Human Services, 2010; American Diabetes Association, 2009; American Heart Association, 2009; Kushi, Byers, Doyle, Bandera, McCullough, Gansler, et al., 2006; Nishida, Uauy, Kumanyika, Shetty, 2004; Van Duyn \& Pivonka, 2000).

The practice and development of critical thinking skills are integral to the educational experience college provides. Being able to use information to develop strategies and reach 
appropriate decisions is a primary objective of a college education (University of Tennessee, Chattanooga, 2011). The premise that knowledge influences behavior via critical thinking and behavioral decision-making is fundamental to many college health education programs and the benefits of eating fruits and vegetables make their promotion an important element of any disease prevention program. Student health center programs and basic nutrition courses have been implemented in an effort to influence students' food choices and increase the amount of fruits and vegetables they consume (Ha \& Caine-Bish, 2009; Mitchell, 1990).

The National College Health Assessment (NCHA) reported that $54.8 \%$ of college students surveyed received nutrition information from their university; however, only $5.9 \%$ of these same students reported eating the recommended five fruits and vegetables a day (American College Health Association, 2009). Other research provides additional support that college students are not meeting the USDA recommended five fruits and vegetables a day (Blanchard et al., 2009; Kasparke, Corwin, Valois, Sargent, \& Moris, 2008; Larson et al., 2008). Therefore, having information and critical thinking skills alone does not explain college students' food choices.

Other factors related to food choice decisions have been identified and include, but are not limited to: food preference and taste (Weaver \& Brittin, 2001; Roininen, Lahteenmaki, \& Tuorila, 1999; Brug, Debie, van Assema, \& Weijts, 1995), gender differences related to food choice (Kandiah, Yake, \&Willett, 2008; Wardle et al., 2004; Oliver, Wardle, \& Gibson, 2000), the personal meaning individuals give food, i.e., food eaten for special celebrations or food eaten for comfort (Delormier, Frohlich, \& Potvin, 2009; Roininen, Lahteenmaki, \& Tuorila, 1999), increased stress levels (Kandiah, Yake, \&Willett, 2008; Serlachius, Hamer, \& Wardle, 2007; Kandiah, Yake, Jones, \& Meyer, 2006), and external/environmental factors such as convenience/availability, the cost of food (Hoffman, 2012; Smith, 2004; Knutson, 2000) and living arrangements (Brunt \& Yeong, 2008)
Investigating separate factors provides insight into what influences food choice, and the variety of factors that have been researched demonstrates the complexity of food choice decisions. However, the application of the results from these studies must be kept within the context of the factor studied. This limits the generalizability and application usefulness of the research. For example, studies that report on how convenience affects food choice may not consider the influence of stress or food preference; behavior change interventions that use these studies as evidence have only the factor of convenience as a variable to modify. It may be more advantageous for health educators to have a model that would provide a method for evaluating an individual's decision making process, as opposed to studying influencing factors separately as they relate to individual behavior decisions.

The Multi-Attribute Utility (MAU) model provides a framework for understanding how decisions are made not based on separate personal or environmental factors, but rather on the utility an individual gives the possible consequences (outcomes) of a decision. This framework was first used to investigate adolescent smoking initiation (Weiss, Edwards, \& Mouttapa, 2009), and its application helps to explain why people can sometimes make seemingly irrational decisions (Weiss \& Weiss, 2012). Therefore, the purpose of this study was to explore the association between decisionmaking and eating behaviors (fruit and vegetable consumption) among college students using the Multi-Attribute-Utility model as the theoretical framework. Providing additional empirical evidence may support its usefulness as a framework for the development of health behavior interventions.

\section{Multi-Attribute-Utility Model}

The Multi-Attribute Utility (MAU) model is a decision making model that is an extension of the Subjective Expected Utility (SEU) theory (Weiss \& Weiss, 2009). In short, the SEU theory posits that decisions are the result of the cost-benefit analysis of the expected outcomes for a particular decision (Weiss, Weiss, \& Edwards, 2010; Edwards, 1954). Outcome 
expectancies have been used as an independent variable in many studies dealing with alcohol use and initiation (Weiss \& Weiss, 2009; Park, 2004; Wall, Thrussell, \& Lalonde, 2003; Fromme \& Dunn, 1992), and have been found to be a better predictor of behavior than attitudes when evaluating alcohol-drinking behaviors (McMahon \& Jones, 1994).

SEU prescribes that individuals should make decisions based upon the summation of the products of the weighted perceived value and the weighted perceived likelihood for potential outcomes of a decision. For example, when making a decision on a major purchase, individuals often make a list of the pro and cons (potential outcomes) for each purchase choice. Outcomes on the "pro" list have been assigned a higher value than outcomes on the "con." Additionally, outcomes that are perceived as less likely to happen are given less weight than those that are highly likely. If the individual actually assigned numbers to these value and likelihood judgments, SEU would prescribe that the individual multiply the value of an outcome with the likelihood of the same outcome. These products would then be summed, and the purchase choice with the highest score is the logical choice. The SEU model has long been appreciated for providing a theoretically grounded basis for making economic decisions. This prescriptive model predicts how things should occur based on logical norms and/or rules. The decision maker weights in his/her mind the value and likelihood of all possible outcomes of an action, applies the mathematical SEU formula, and calculates the answer for which outcome is optimal (von Winterfeldt \& Edwards, 1986).

The applicability of the SEU model was greatly expanded when decision analysts realized that non-economic decisions could be conceptualized similarly, with important individual noneconomic decisions usually having multiple consequences attached to them (Keeney \& Raiffa, 1976; Shepard, 1964). For example, the choice to eat fruits and vegetables has a number of potential consequences (outcomes): satisfying hunger, costing more money, decreasing risk of disease, helping maintain weight, etc. The generalized version of this expanded theory is known as the Multi-Attribute-Utility (MAU) model. In a study by Weiss, Weiss and Edwards (2010), the authors proposed to extend the MAU model further, applying it descriptively to the decisions that people make every day. By incorporating a new parameter "momentary salience" into the model, they provide a modification that makes the MAU model descriptive, as it helps to explain the unexpected choice. The new parameter captures the idea that the attractiveness and desirability of a decisional option may depend on what is happening right now, and may be contrary to one's general values at times. Momentary salience explains why an apparently sensible teenager might take up cigarette smoking or ingest an unknown drug at a party. The attractiveness of being accepted by peers or escaping from reality may override the known negative consequences of substance use. The key feature of this descriptive MAU model is that each decision option, i.e., to smoke or not to smoke, has a set of anticipated consequences attached to it (e.g., getting in trouble, being accepted by peers); the consequences, whether intended or not, are judged and weighted by the individual in terms of their value, likelihood and importance, and are the "attributes" of that behavior option (Weiss \& Weiss, 2009). For example, adolescents who value being accepted by their peers, who believe that smoking will increase the likelihood of this happening, and who place the greatest importance (highest priority) on peer acceptance will most likely take a cigarette offered to them by a peer.

Weiss, Weiss and Edwards (2010) propose that three aspects of each expected consequence attached to a behavior option determine how it contributes to the utility of the decision option. This deconstruction gives rise to three model parameters attached to each consequence. Whenever a moment of decision arises, consequences for one specific decision choice are evaluated using the three parameters in accordance with the following mathematical expression:

$$
\mathrm{MAU}=\Sigma_{j} \mathrm{SV}_{\mathrm{j}} \bullet \mathrm{SP}_{\mathrm{j}} \bullet \mathrm{MS}_{\mathrm{j}}
$$


where $\mathrm{j}$ indexes the consequences anticipated by the decision maker if he/she chooses that option. The utility score of each outcome being evaluated is mathematically determined by the multiplicative products of all three consequencecomponents (von Winterfeldt \& Edwards, 1986). The behavior option with the highest sum of utility scores (MAU) is the outcome that an individual ultimately chooses.

Subjective value (SV) is the perceived worth of the consequence, is notated with a positive or negative value, and ranges from -3 to +3 (Weiss \& Weiss, 2010; von Winterfeldt \& Edwards, 1986). When making a food choice decision, individuals assign a separate value to each possible consequence (outcome) of that decision. The assigned value can be either positive or negative, depending on participants' perceived value of each outcome of the option they choose. In this study, SV addresses whether an individual chooses healthy versus nonhealthy food (fruit and vegetable consumption) based on their perceived value of the outcomes of eating a healthy diet.

Subjective Probability (SP), or Subjective Likelihood, is the perceived likelihood that a consequence will occur given the particular choice (decision) is made (Weiss \& Weiss, 2010; von Winterfeldt \& Edwards, 1986). Subjective probability ranges between $0(0 \%$ perceived chance of the consequence happening) and $1 \quad(100 \%$ perceived chance of the consequence happening).

Momentary salience (MS) is the importance of a consequence to the person at the very moment of a particular choice (decision) is made (Weiss \& Weiss, 2010). Importance is specifically meant to reflect how much the consequence matters at the moment of making a particular choice (decision). MS ranges between 0 and 1 , with a 0 indicating the outcome is of no significance (low priority) to the decision maker at the moment of the decision. This adaptation localizes the differences between two different individuals when evaluating value and importance at the moment. Two individuals may both acknowledge a consequence as positive, and both may think it is likely to occur. However, the importance of a particular consequence may differ greatly between the individuals, as they may have different overriding priorities. The addition of the momentary salience constructs gives additional strength to the MAU theory, as this construct takes into consideration the influences of a decision at the point the decision is made depending on time and situation. This feature helps explain why college students who might intend to eat a healthy diet sometimes make unhealthy choices (Weiss \& Weiss, 2009).

The product of SV, SP, and MS for a single consequence provides the total utility of that consequence for an individual. In this study, if the total utility for a consequence of choosing a healthy diet is negative, that consequence will influence the individual (college student) to be less likely to choose healthy food, whereas if the total utility for a consequence of choosing a healthy diet is positive, the consequence will influence the individual to be more likely to choose healthy food. Therefore, the summation of the all the total utility scores for the consequence of the MAU model will equal the total utility for the evaluation of food intake among college students. This study suggests that the higher the MAU score, the more likely a college student will decide to choose healthy food.

\section{The Present Study}

While college students have knowledge of good eating practices, their behavior reveals inadequate fruit and vegetable consumption. The purpose of this study is to investigate college students' food choice using the Multi Attribute Utility model and evaluate the model's ability to predict food choice. Further, the relationships of the total utility for the consequences of food choice versus actual food choice will be of interest, as it will provide insight into the decisional priorities of college students when they decide what to eat. As the relationship between the MAU parameters and food choices is illuminated, designers of health behavior interventions can target the consequences where there is a difference between healthy and lesshealthy eaters. Knowing the consequences that have the greatest influence on college students when they make food choices will be valuable in 
designing interventions that will have life-long returns.

\section{Methods}

\section{Sample}

A convenience sample of 406 participants was recruited from courses representing all the colleges and departments within a large, public university in Southern California during the spring 2009 semester.

\section{Procedures}

The data used for this study came from a larger CDC funded data collection and followed procedures approved by the University's Institutional Review Board. Trained research assistants collected data during classroom visits using a 221-item Student Health Survey; 27 of the items on this survey measured the constructs of the MAU model related to eating a healthy diet. Items were adopted from previously published studies (Reid, Bunting, \& Hammersley, 2005; Brug, Debie, van Assema \& Weijts, 1995) and reviewed by the research team for face validity. Cronbach's alphas for the 9 items of subjective value was $\alpha=.636$; 9 items of subjective likelihood was $\alpha=.722$, and 9 items of momentary salience was $\alpha=.725$. Students' participation was voluntary, with completers receiving a $\$ 10$ gift card. To prevent double sampling due to a student being in multiple classes, students were asked not to participate if they completed the questionnaire in another class.

Food intake information was collected over seven consecutive days using a 27-item online tool delivered via SurveyMonkey, with the two items reporting fruit and vegetable consumption used for this study. The food intake questions were developed using recall survey methods already established and were adapted in accordance with the U.S. Department of Agriculture's (USDA) Food Pyramid Guide (U.S Department of Agriculture, 2009). SurveyMonkey allowed a unique copy of the food intake log to be sent to participants at 4:00 p.m. each day for that day's food intake. Each day's food intake log closed at 12:00 noon the following day, with a new questionnaire sent at 4:00 p.m. for the current day's intake. Paper copies of the food intake log were provided to participants in case they did not have access to the Internet. Text messages were sent at 8:30 p.m. (eztexting.com) to remind participants to complete the online food intake logs; an opt-out option was given, and approximately $50 \%$ of participants requested text message reminders. Because the momentary salience survey asked participants to indicate the importance of eating a healthy diet at the moment they make the decision, the food intake logs were completed the week immediately following the paper survey in an attempt to maintain temporal relevance.

\section{Measurements}

\section{Fruit and Vegetable Consumption}

The dependent variable for this study was the amount of fruits and vegetables consumed each day. Because an online survey tool was used, participants were first asked, "how often" they ate vegetables that day. If they answered, "none," the survey skipped the next item, "how much," and their intake was recorded as zero for that day. For those who answered more than none to "how often," they were asked: "Vegetables (broccoli, onion, celery, lettuce, etc.) In general, 1 cup of the vegetable group can be considered from 1 cup of raw or cooked vegetables, 1 cup of $100 \%$ vegetable juice, or 2 cups of raw leafy greens. HOW MUCH of these items did you eat TODAY? (total amount)." The "how often" and "how much" items were repeated for fruits, with the "how much" statement: "Fruits (apple, melon, pear, kiwi, etc.) In general, 1 cup of the fruit group can be considered from 1 cup of cut fruit, 1 cup of $100 \%$ juice, or $1 / 2$ cup of unsweetened dried fruit. HOW MUCH of these items did you eat TODAY? (total amount)." Choices for both "how much" items were "about $1 / 2$ cup," "about 1 cup," "about 2 cups," or "more than 2 cups." 
The daily cups of fruit and vegetables were added together and then averaged over seven days.

\section{High Fruit and Vegetable $(F \& V)$ eaters and} Low $F \&$ V eaters

High $\mathrm{F} \& \mathrm{~V}$ eaters were defined as those who eat a seven day average of four fruits plus vegetables a day; low $\mathrm{F} \& \mathrm{~V}$ eaters were defined as those who ate a seven day average of zero fruits plus vegetables a day. The average number of cups was rounded to the closest whole number. While the USDA recommendation is five cups (previously servings) of fruit plus vegetables a day, none of the participants in the sample achieved the recommendation to allow its use for classification. In an attempt to align as near as possible with the USDA guidelines for fruits plus vegetables consumption for good health, high F \& V eaters were defined as those who ate four or more cups of fruits and vegetables a day. Low $\mathrm{F} \& \mathrm{~V}$ eater were defined as those who ate none. This resulted in a smaller sample for analysis (58 participants or $14.3 \%$ of total sample), but it also removed ambiguity of defining those who ate one, two or three cups a day as healthy or less healthy. Looking at the ends of the curve allowed for the comparisons of the means of the consequences of eating a healthy diet for two groups who were truly different in their behavior choices as related to fruit and vegetable consumption.

\section{Multi-Attribute Utility Parameters}

The independent variables used for this study were the three attributes of the Multi-Attribute Utility theory: subjective value, subjective likelihood (probability), and momentary salience (importance) of an expected consequence (outcome) of eating a healthy diet; the product of SV, SP and MS for each outcome; and, the MAU (total utility) score. These constructs were assessed using the methods proposed by Weiss, Weiss, and Edwards (2009). Instructions for the items pertaining to Multi Attribute Utility parameters measurement included the definition of a healthy diet, which was defined as, "A healthy diet includes foods that have a large amount of key nutrients, like vitamins and minerals, low-fat and nonfat dairy, whole grains, fruits and vegetables, lean meats, seafood, beans and nuts."

The nine expected outcomes that were presented to participants were "feeling energetic," "spending a little more money," "looking good," "enjoying the taste of the food," "lowering my risk of diseases associated with obesity," "taking a lot of time to prepare the food," "feeling like I am in control of my own behavior," "eliminating my hunger," and "feeling satisfied and happy." The goal in constructing the list was to choose consequences that are independent (to yield proper weighting) and exhaustive (to ensure that the important consequences are examined). The process of constructing the consequence list was simplified by adopting items from previous published studies, such as food expectancy questionnaires (Reid, Bunting, \& Hammersley, 2005), and positive and negative statements about fruit and vegetable consumption (Brug, Debie, van Assema \& Weijts, 1995). These consequences attempt to cover the physical, psychological and social dimensions of the possible consequences of eating a healthy diet.

\section{Subjective Value}

For each of the nine consequences, participants were asked to rate how much they value eating a healthy diet with the given prompt, "If I eat a healthy diet, I think __ is ..." followed by the list of consequences. They were asked to respond regardless of whether or not they currently eat a healthy diet. Because subjective value is asking for a rating of good or bad, responses were coded in both the positive and negative direction. Responses were $-3=$ "Extremely Bad," -2 = "Very Bad," -1 = "Bad," $0=$ "Neither Good nor Bad," 1 = "Good," 2 = "Very Good," or 3 = "Extremely Good."

\section{Subjective Likelihood}

Participants were asked to rate how likely or unlikely they thought each consequence would actually occur if they ate a healthy diet. They were asked to respond regardless of whether or not they currently eat a healthy diet. The prompt read, "If I eat a healthy diet, I think the likelihood of __ is . . ." followed by thelist of the consequences. Responses were $0=$ 
"Completely Unlikely," 1 = "Very Unlikely," 2 = "Unlikely," 3 = "Likely," 4 = "Very Likely," or $5=$ "Completely Likely."

\section{Momentary Salience}

Participants were asked to rate the importance of eating a healthy diet right now based on the different consequences. Again, participants were asked to respond regardless of whether or not they currently eat a healthy diet. Momentary salience was assessed using the prompt, "When choosing whether or not to eat a healthy meal I think __ is ..." followed by the list of expected outcomes. Responses were $0=$ "Not important at all," $1=$ "Slightly Important," $2=$ "Moderately Important," 3 = "Very Important," or $4=$ "Extremely Important." Momentary salience included additional instructions to assist in capturing the importance participants place on eating a healthy diet in the future: "Keep in mind that a consequence that you think is important in general may not be that important to you at the moment you make food choices. For example, looking good may be important to you. However, looking good may not be important to you at the moment you choose a meal."

The product for each of the nine consequences was calculated by multiplying subjective value, subjective likelihood and momentary salience of each consequence attached to food choices. The total MAU model score was the sum of these nine products.

\section{Data Analysis}

Analysis was completed using SPSS Statistics 20 for Windows. Gender, ethnicity and class standing frequencies and percentages were calculated, along with the mean and standard deviation for age and the average number of fruits, vegetables, and fruits plus vegetables consumed over the course of seven days was computed. The frequency of high $\mathrm{F} \& \mathrm{~V}$ and low $\mathrm{F} \& \mathrm{~V}$ eaters was also calculated along with the mean and standard deviation for fruits plus vegetables for both groups.

Analysis of MAU as a predictor of eating fruits and vegetables was conducted using linear regressions. Data from the larger sample of 406 participants was used for this calculation. With
MAU as the independent variable, linear regressions were calculated for dependent variables fruit consumption, vegetable consumption and fruit plus vegetable consumption (seven day average for all). Gender and ethnicity were also placed into the model to evaluate them as potential covariates for fruit plus vegetable consumption.

Independent samples t-tests were used to compare differences between high $\mathrm{F} \& \mathrm{~V}$ eaters and low $\mathrm{F} \& \mathrm{~V}$ eaters on the means of the individual MAU parameters for each consequence (subjective value, subjective likelihood, and momentary salience) for all nine consequences. Hence, a total of $3 \times 9=27$ comparisons were made. Last, we compared the utility score (the product of the three parameters) for each of the 9 consequences. High and low F \& V eaters were compared on these 9 utility scores. Dichotomizing the group, while reducing the sample size analyzed, allowed for a deconstruction of the MAU framework and the evaluation of the contribution of each parameter and consequence to eating fruits and vegetables. It also provided data that could be easily graphed for visual comparison.

\section{Results}

\section{Demographics}

The sample was comprised of 138 males (34\%) and 268 females (66\%). The mean age was $23.12+4.78$ years and the sample was ethnically diverse with $124(30.5 \%)$ being non-Hispanic White, 112 (27.8\%) Asian/Pacific Islanders, 104 (25.6\%) Hispanic/Latinos, $16 \quad$ (3.9\%) Black/African Americans, and 50 (12.0\%) Multi-race/ethnicity or other. The majority of participants were upperclassmen, with 357 $(88.3 \%)$ reporting having junior or senior standing.

\section{Food Choices}

Overall, the participants reported eating more vegetables than fruit, with the seven-day average vegetable consumption of 0.97 cups $(\mathrm{SD}=0.57$ ) and the daily fruit consumption of 0.70 cups (SD $=0.59)$. Combined, participants reported eating a seven day average of 1.67 cups $(\mathrm{SD}=0.97)$ of fruit plus vegetables daily. Females consumed a 


\section{Figure 1}

Mean Value of Each Consequence (Subjective Value), $n=406$

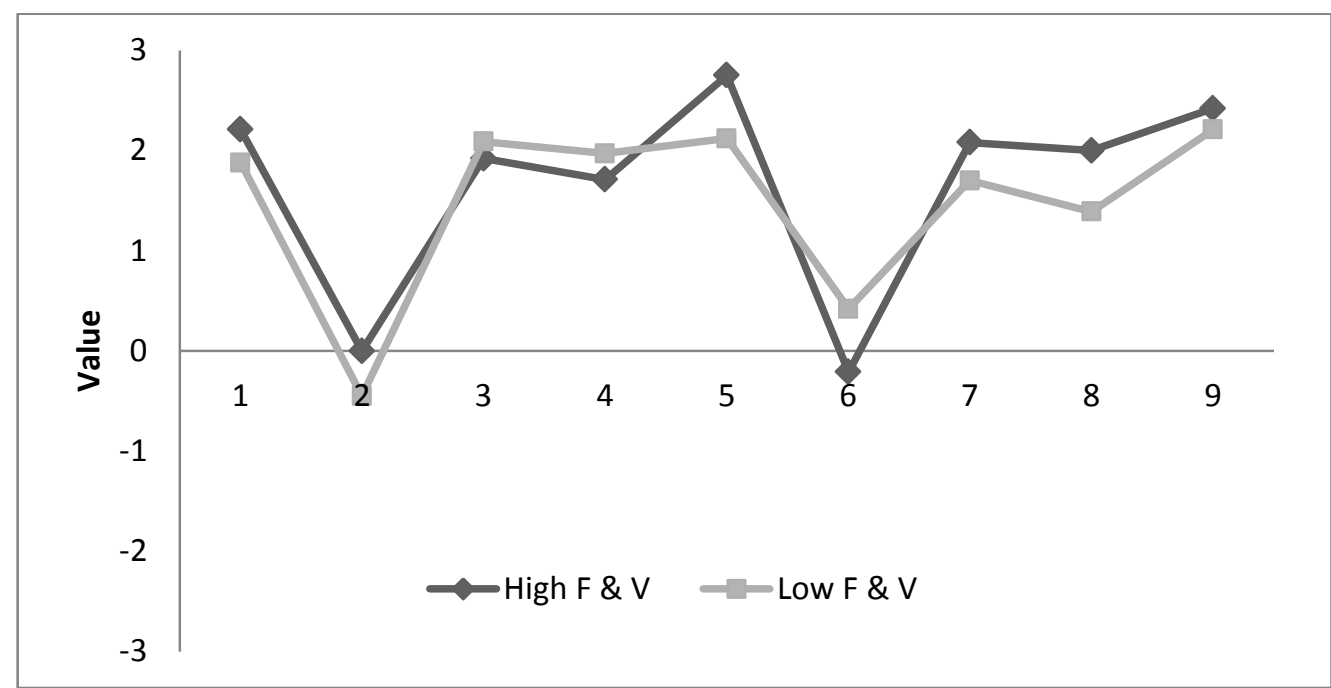

Note: High F \& V (4+ cups of fruits plus vegetables a day) versus Low F \& V ( 0 cups of fruits plus vegetables a day)

\section{Table 1}

\section{Mean Value of Each Consequence (Subjective Value), $n=406$}

\begin{tabular}{|c|c|c|c|c|c|c|c|}
\hline \multirow[b]{2}{*}{ Value of Consequence } & \multicolumn{2}{|c|}{ Total Sample } & \multicolumn{2}{|c|}{ High F \& V } & \multicolumn{2}{|c|}{ Low F \& V } & \multirow[b]{2}{*}{$p$} \\
\hline & $\mathrm{M}$ & $S D$ & $\mathrm{M}$ & $S D$ & $\mathrm{M}$ & $S D$ & \\
\hline 1. Feeling energetic & 2.02 & 1.13 & 2.21 & 0.98 & 1.88 & 1.21 & .279 \\
\hline 2. Spending a little more money & -0.26 & 1.13 & 0.00 & 1.02 & -0.45 & 1.18 & .134 \\
\hline 3. Looking good & 2.02 & 1.03 & 1.92 & 1.24 & 2.09 & 0.84 & .532 \\
\hline 4. Enjoying the taste of the food & 1.86 & 0.97 & 1.71 & 1.08 & 1.97 & 0.88 & .320 \\
\hline $\begin{array}{l}\text { 5. Lowering my risk of diseases } \\
\text { associated with obesity** }\end{array}$ & 2.39 & 0.98 & 2.75 & 0.53 & 2.12 & 1.14 & .008 \\
\hline $\begin{array}{l}\text { 6. Taking a lot of time to prepare } \\
\text { the food }\end{array}$ & 0.05 & 1.23 & 0.42 & 0.97 & -.21 & 1.34 & .056 \\
\hline $\begin{array}{l}\text { 7. Feeling like I am in control of } \\
\text { my own behavior }\end{array}$ & 1.86 & 1.08 & 2.08 & .881 & 1.70 & 1.19 & .183 \\
\hline 8. Eliminating my hunger & 1.65 & 1.46 & 2.00 & 1.47 & 1.39 & 1.41 & .122 \\
\hline 9. Feeling satisfied and happy & 2.30 & 0.91 & 2.42 & .929 & 2.21 & .893 & .408 \\
\hline
\end{tabular}




\section{Figure 2}

Mean Likelihood of Each Consequence (Subjective Likelihood), n=406

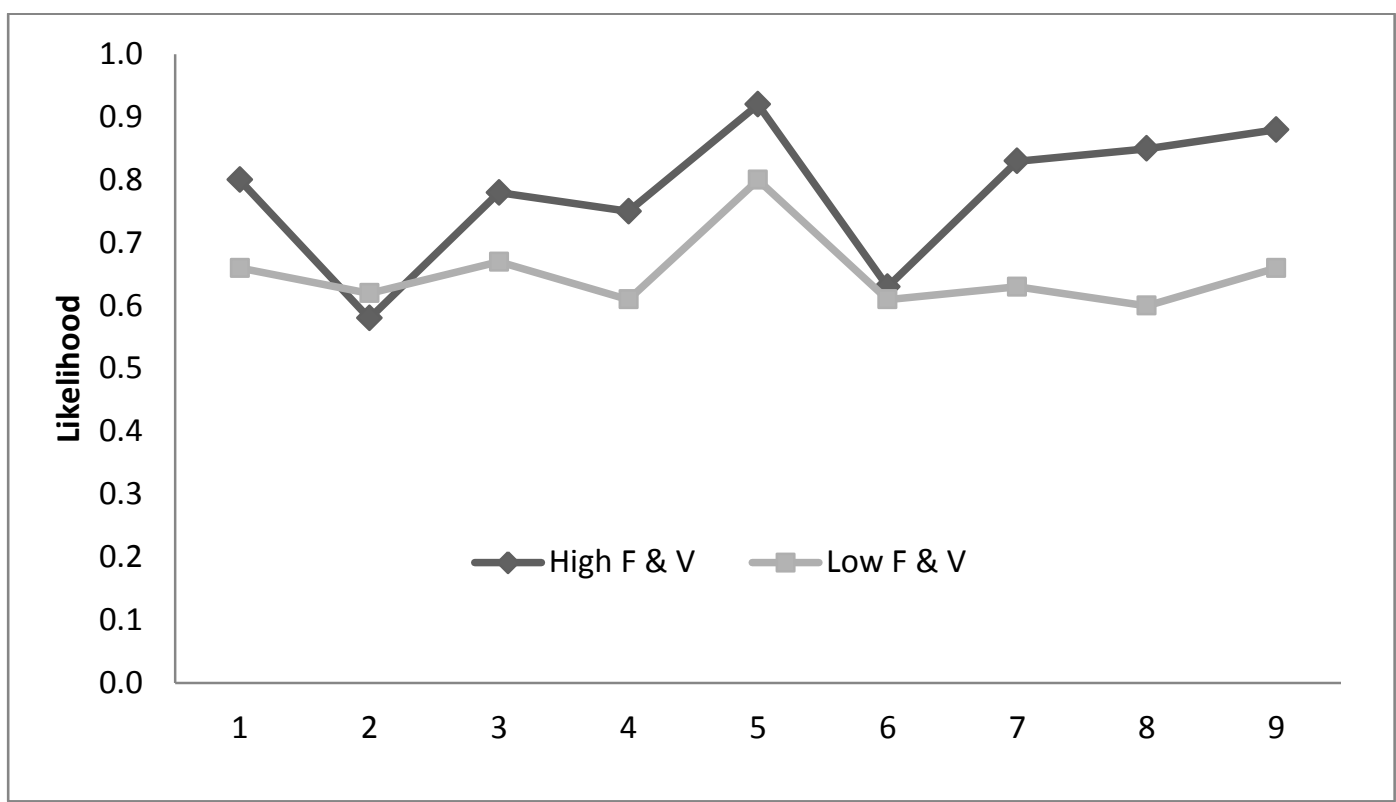

Note: High F \& V (4+ cups of fruits plus vegetables a day) versus Low F \& V ( 0 cup of fruits plus vegetables a day) eaters

Table 2

Mean Likelihood of Each Consequence (Subjective Likelihood), n=406

\begin{tabular}{|c|c|c|c|c|c|c|c|c|}
\hline \multirow{2}{*}{\multicolumn{2}{|c|}{ Likelihood (Probability) of Consequence }} & \multicolumn{2}{|c|}{ Total Sample } & \multicolumn{2}{|c|}{ High F \& V } & \multicolumn{2}{|c|}{ Low F \& V } & \multirow[b]{2}{*}{$p$} \\
\hline & & $\mathrm{M}$ & $S D$ & $M$ & $S D$ & $\mathrm{M}$ & $S D$ & \\
\hline 1. & Feeling energetic** & 0.72 & 0.24 & 0.80 & 0.20 & 0.66 & 0.26 & .032 \\
\hline 2. & Spending a little more money & 0.61 & 0.22 & 0.58 & 0.20 & 0.62 & 0.24 & .500 \\
\hline 3. & Looking good* & 0.71 & 0.19 & 0.78 & 0.15 & 0.67 & 0.20 & .031 \\
\hline 4. & Enjoying the taste of the food $* *$ & 0.67 & 0.21 & 0.75 & 0.20 & 0.61 & 0.20 & .012 \\
\hline 5. & $\begin{array}{l}\text { Lowering my risk of diseases } \\
\text { associated with obesity** }\end{array}$ & 0.85 & 0.17 & 0.92 & 0.12 & 0.80 & 0.19 & .009 \\
\hline 6. & Taking a lot of time to prepare the food & 0.62 & 0.18 & 0.63 & 0.19 & 0.61 & 0.17 & .657 \\
\hline 7. & $\begin{array}{l}\text { Feeling like } \mathrm{I} \text { am in control of } \mathbf{m y} \\
\text { own behavior**** }\end{array}$ & 0.71 & 0.23 & 0.83 & 0.16 & 0.63 & 0.24 & .001 \\
\hline 8. & Eliminating my hunger**** & 0.71 & 0.24 & 0.85 & 0.17 & 0.60 & 0.22 & .000 \\
\hline 9. & Feeling satisfied and happy*** & 0.75 & 0.23 & 0.88 & 0.16 & 0.66 & 0.23 & .000 \\
\hline
\end{tabular}




\section{Figure 3}

Mean Importance of Each Consequence (Momentary Salience), $n=406$

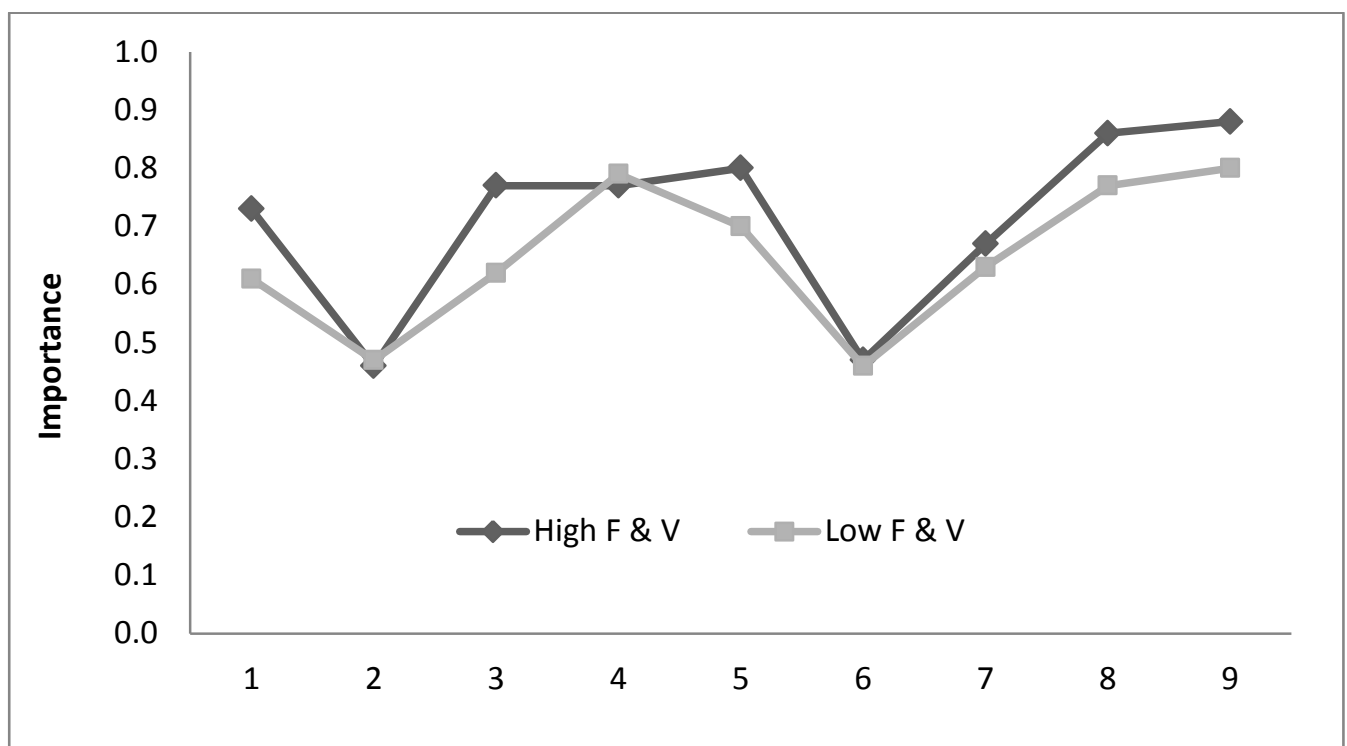

Note: High F \& V (4+ cups of fruits plus vegetables a day) versus Low F \& V ( 0 cup of fruits plus vegetables a day) eaters

Table 3

Mean Importance of Each Consequence (Momentary Salience), $n=406$

\begin{tabular}{|c|c|c|c|c|c|c|c|}
\hline & \multicolumn{2}{|c|}{ Total Sample } & \multicolumn{2}{|c|}{ High F \& V } & \multicolumn{2}{|c|}{ Low F \& V } & \multirow[b]{2}{*}{$p$} \\
\hline Importance of Consequence & M & $S D$ & $\mathrm{M}$ & $S D$ & M & $S D$ & \\
\hline 1. Feeling energetic & 0.66 & 0.27 & 0.73 & 0.21 & 0.61 & 0.29 & .084 \\
\hline 2. Spending a little more money & 0.46 & 0.23 & 0.46 & 0.22 & 0.47 & 0.25 & .858 \\
\hline 3. Looking good* & 0.68 & 0.24 & 0.78 & 0.22 & 0.62 & 0.24 & .020 \\
\hline 4. Enjoying the taste of the food & 0.78 & 0.20 & 0.77 & 0.19 & 0.79 & 0.20 & .748 \\
\hline $\begin{array}{l}\text { 5. Lowering my risk of diseases } \\
\text { associated with obesity }\end{array}$ & 0.74 & 0.28 & 0.80 & 0.29 & 0.70 & 0.27 & .163 \\
\hline 6. Taking a lot of time to prepare the food & 0.46 & 0.27 & 0.47 & 0.31 & 0.46 & 0.25 & .929 \\
\hline $\begin{array}{l}\text { 7. Feeling like I am in control of my own } \\
\text { behavior }\end{array}$ & 0.64 & 0.27 & 0.67 & 0.23 & 0.63 & 0.30 & .607 \\
\hline 8. Eliminating my hunger & 0.81 & 0.21 & 0.86 & 0.18 & 0.77 & 0.22 & .079 \\
\hline 9. Feeling satisfied and happy & 0.83 & 0.20 & 0.88 & 0.15 & 0.80 & 0.22 & .131 \\
\hline
\end{tabular}




\section{Figure 4}

Mean Product of Value, Likelihood and Momentary Salience for Each Consequence, n= 406

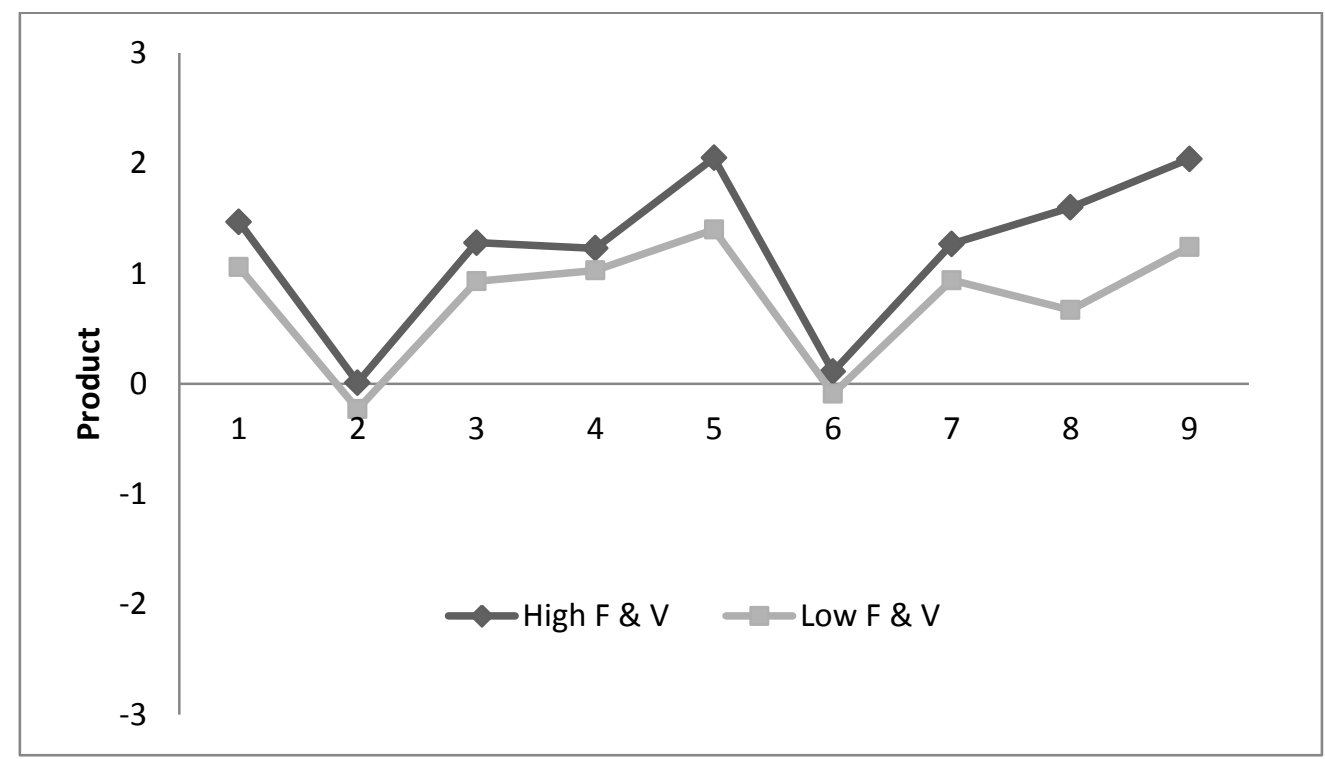

High F \& V (4+ cups of fruits plus vegetables a day) versus Low F \& V ( 0 cup of fruits plus vegetables a day) eaters

Table 4

Mean Product of Value, Likelihood and Momentary Salience for Each Consequence, $n=406$

\begin{tabular}{|c|c|c|c|c|c|c|c|}
\hline & \multicolumn{2}{|c|}{ Total sample } & \multicolumn{2}{|c|}{ High F \& V } & \multicolumn{2}{|c|}{ Low F \& V } & \multirow[b]{2}{*}{$p$} \\
\hline Product for Consequence & $\mathrm{M}$ & $S D$ & $\mathrm{M}$ & $S D$ & M & $S D$ & \\
\hline 1. Feeling energetic & 1.23 & 0.93 & 1.47 & 1.00 & 1.06 & 0.91 & .107 \\
\hline 2. Spending a little more money & -0.13 & 0.68 & 0.01 & .507 & -0.23 & 0.77 & .194 \\
\hline 3. Looking good & 1.78 & 0.96 & 1.28 & 1.13 & 0.93 & 0.79 & .177 \\
\hline 4. Enjoying the taste of the food & 1.11 & 0.91 & 1.23 & 1.08 & 1.03 & 0.78 & .419 \\
\hline $\begin{array}{l}\text { 5. Lowering my risk of diseases } \\
\text { associated with obesity* }\end{array}$ & 1.68 & 1.10 & 2.05 & .956 & 1.40 & 1.13 & .026 \\
\hline 6. Taking a lot of time to prepare the food & -0.01 & 0.54 & 0.11 & 0.42 & -.092 & 600 & .156 \\
\hline $\begin{array}{l}\text { 7. Feeling like I am in control of my own } \\
\text { behavior }\end{array}$ & 1.08 & 0.99 & 1.27 & 0.90 & 0.94 & 1.04 & .206 \\
\hline 8. Eliminating my hunger** & 1.06 & 1.31 & 1.60 & 1.45 & .674 & 1.05 & .005 \\
\hline 9. Feeling satisfied and happy*** & 1.58 & 1.02 & 2.04 & 1.11 & 1.24 & .824 & .001 \\
\hline
\end{tabular}

Note. $* \mathrm{p}<.05, * * \mathrm{p}<.01, * * * \mathrm{p}<.001$ 
seven day average of 0.71 cups $(\mathrm{SD}=0.58)$ of fruit, 1.02 cups $(\mathrm{SD}=0.58)$ of vegetables, and 1.73 cups $(\mathrm{SD}=0.95)$ of fruits plus vegetables. Males consumed a seven day average of 0.67 cups $(\mathrm{SD}=0.59)$ of fruit, 0.88 cups $(\mathrm{SD}=0.55)$ of vegetables, and 1.55 cups $(\mathrm{SD}=1.00)$ of fruits plus vegetables. These amounts are well below the recommendation made by the USDA of 4.5 cups of fruits plus vegetables for the average female and 5 cups of fruits plus vegetables for the average male. There were no significant differences between males and females on these outcomes.

There were a total of 25 high $\mathrm{F} \& \mathrm{~V}$ eaters $(\mathrm{M}=$ 3.95 cups, $\mathrm{SD}=.371$ ) with two participants reporting 4.7 cups seven day average, and 33 low $\mathrm{F} \& \mathrm{~V}$ eaters $(\mathrm{M}=0.28$ cups, $\mathrm{SD}=.137)$. There was a significant difference in the seven day average of cups of fruit plus vegetables consumed between the groups $(p=.000)$.

\section{MAU as a Predictor of Fruit and Vegetable Consumption}

Linear regressions revealed that MAU was a significant predictor of average daily fruit consumption, $\beta=.131, \mathrm{t}(406)=2.657, \mathrm{R} 2=$ $.017, \mathrm{~F}(1,406)=7.062, \mathrm{p}=.008$; vegetable consumption, $\beta=.160, \mathrm{t}(406)=3.251, \mathrm{R} 2=$ $.025, \mathrm{~F}(1,406)=10.571, \mathrm{p}=.001 ;$ and fruit plus vegetable consumption $\beta=.174, \mathrm{t}(406)=3.549$, $\mathrm{R} 2=.030, \mathrm{~F}(1,406)=12.599, \mathrm{p}=.000$. Entering gender into the model slightly improved the relationship for fruit plus vegetable consumption $\beta=.118, \mathrm{t}(406)=2.419$, $\mathrm{R} 2=.014, \mathrm{~F}(1,406)=9.301, \mathrm{p}=.016$, while ethnicity had no effect on fruit plus vegetable consumption $\beta=.015, \mathrm{t}(406)=0.297, \mathrm{R} 2=$ $.000, \mathrm{~F}(1,406)=6.216, \mathrm{p}=.766$.

\section{Differences in Parameters of MAU between High and Low F \& V Eaters}

The individual parameters of total MAU were assessed for high $\mathrm{F} \& \mathrm{~V}$ and low $\mathrm{F} \& \mathrm{~V}$ eaters by computing t-tests to determine if there were significant differences in means of subjective value, subjective likelihood, momentary salience, and the product of the three parameters for each consequence.
Subjective value and momentary salience had only one consequence that showed a significant difference between the high F \& V and low F \& $\mathrm{V}$, "lowering my risk of diseases associated with obesity" $(\mathrm{p}=.008)$ and "looking good" $(\mathrm{p}=$ .020) respectively. There were seven consequences that were significantly different between groups for subjective likelihood: "feeling energetic" $(p=.032)$, "looking good" ( $p$ $=.031)$, "enjoying the taste of the food" $(\mathrm{p}=$ .012), "lowering my risk of diseases associated with obesity" ( $p=.009)$, "feeling like I am in control of my own behavior" $(\mathrm{p}=.001)$, "eliminating my hunger" $(\mathrm{p}=.000)$, and "feeling satisfied and happy" $(\mathrm{p}=.000)$. Products of the parameters were significantly different for the consequences "lowering my risk of diseases associated with obesity" $(\mathrm{p}=.026)$, "eliminating my hunger" $(p=.005)$, and "feeling satisfied and happy" $(\mathrm{p}=.001)$. Figures $1-4$ provide a summary of this data.

\section{Discussion}

Previous studies on college students' food choices have focused on how individual factors such as knowledge of proper nutrition, cost, convenience, living conditions, gender, stress and the meaning of food influence choice. The purpose of this study was to investigate college students' food choices (fruit and vegetable consumption) as they related to the decisionmaking process using the Multi-Attribute Utility model as a framework.

Multi-Attribute Utility model showed to be a predictor of college students' food choices (fruits and vegetables). A linear regression resulted in a significant, though small, relationship between MAU and fruit plus vegetable consumption. This relationship remained even when controlled for gender and ethnicity.

There was also a significant difference between high $F \& V$ and low $F \& V$ for a variety of consequences across the parameters of MAU, with subjective likelihood having the greatest number of consequences that were significantly 
different. Though not all consequences were statistically different between groups, there most often appears to be even small differences for the SV, SP, MS, and products of the consequences between groups when viewing the data graphically (Figures $1-4$ ).

It is possible that the current data yielded only a modest relationship because it was taken from a larger data collection, and the behavior choice presented on the MAU survey was "eating a healthy diet." The survey also included the definition of "healthy diet" as, "A healthy diet includes foods that have a large amount of key nutrients, like vitamins and minerals, low-fat and nonfat dairy, whole grains, fruits and vegetables, lean meats, seafood, beans and nuts." While the inclusive language allowed for the analysis of MAU with other food choices that are considered healthy and were reported on the 27-item online food intake $\log$, it is possible that it also reduced the strength of using an individual food category in analysis. However, even with the broad scope of "eating a healthy diet," there was a significant relationship between MAU and eating fruits and vegetables. The results, though small, are encouraging and require additional testing with specific language to determine if the relationship between MAU and behavior choice is strengthened.

Using the MAU as a framework provides the opportunity for the evaluation of how subjective value, subjective likelihood, momentary salience and the products of the three parameters for each of the consequences influence a decisional choice. Knowing where there are significant differences between high F \& V and low F \& V eaters provides opportunity for evaluation and insight into what really matters in a decision. For example, looking at subjective value, "lowering my risk of diseases associated with obesity" had the greatest difference of means between groups. This indicates that those who ate fruits or vegetables evaluated this consequence as being good to a greater degree than those who did not eat fruits and vegetables. Interventions that increase college students' value of the protective factors of healthy eating, or that improve their understanding of the disease process and how it begins early in life, would potentially decrease the differences between groups and, theoretically, increase fruit and vegetable consumption.

Evaluating subjective likelihood provides additional possibilities for interventions. The consequences that were significantly different between groups were "looking good," "enjoying the taste of the food," "lowering my risk of diseases associated with obesity," "feeling like I am in control of my own behavior," "eliminating my hunger," and "feeling satisfied and happy." Those who did not eat fruits and vegetables indicated they felt these consequences were less likely to happen than did the healthy eaters. Interventions that improve the likelihood of these consequences should increase fruit and vegetable consumption. For example, an activity that provides good tasting fruits and vegetables to college students will allow them to "enjoy the taste of the food." Small group discussions focused on how students who bring fruits and vegetables to class or pack their lunch feel that they are in "control of their behavior" may improve self-efficacy and increase consumption. Lessons on how eating fruits and vegetables helps students maintain healthy weight may increase the likelihood of "looking good" for students who do not eat fruits and vegetables.

The two consequences with the greatest significant differences in subjective likelihood were "eliminating my hunger," and "feeling satisfied and happy." There are several possible explanations as to why low $\mathrm{F} \& \mathrm{~V}$ eaters perceive eating healthy food will not eliminate their hunger or provide the feelings of satisfaction and happiness. Healthy food is generally low in fat, sugar and salt, three major ingredients in the formulation of fast food. Fat in foods provides satiety, sugar elevates mood (Avena, Rada, \& Hoebel, 2008), and salt has been shown to have addictive properties (Tekol, 2006; Smith, 2004; Knutson, 2000). Fat, salt and sugar are abundant in processed and 
convenience food. Countering these foods' easy "fix" may be one of public health's greatest challenges.

\section{Limitations}

Overall, this sample of students ate fruits and vegetables less frequently than previously presented. The NCHA (2009) survey data reports that college student eat an average of 2.14 servings of fruits and vegetables a day, with $5.2 \%$ consuming five servings of fruits and vegetables a day. With the recent revision of the USDA MyPyramid, and now MyPlate, servings of fruit and vegetables are now reported as cups. The current sample averaged 1.67 cups of fruits and vegetables a day, and not a single participant reported meeting this minimum USDA recommendation of five-a-day. The difference in the reported amount of fruits and vegetables consumed between the current sample and the NCHA samples might be due to how fruit and vegetable consumption was measured. The NCHA questionnaire used a single question, "How many servings of fruits and vegetables do you generally have per day?" with the response choices " 0 ," " 1 - 2 servings," "3 - 4 servings," or "5 or more servings." There is no definition of what constitutes a serving, and there is no time span reference such as "in the past 30 days." The current study used a seven-day average of fruit plus vegetables reported within 24 hours of consumption. It is possible that previously collected data overestimated fruit and vegetable consumption due to limitations in participant recall or participant bias.

The data presented in this study is limited due to the high level of reliance on honest self-reported data. Specifically, participants were asked to report the amount of fruits and vegetables consumed each day for seven days. In an attempt to reduce recall errors, food intake was collected by way of an online food intake log that is sent to the participants each day for that day's food intake. However, self-report may be influenced by recall, social desirability, or motivation, and indirect measures such as self-report have inherent limitations. The differences between actual behavior and reported behavior may influence the accuracy of the findings.
Testing may also influence the internal validity of this study. The food intake log is completed for seven days and the format is the same each day, participants may get into a routine of answers, responding without putting much thought into what they really ate that day. Although it is possible that a testing affect may have occurred, it is probable that the influence will be similar between both groups.

The results of this study may lack external validity and not be generalized to all college populations due to the incidental sampling strategy used to recruit participants. The sample presented here did not fully reflect the University's demographics as hoped, as there was an overrepresentation of upper classmen and females. However, while specific findings presented might not be generalizable, the MAU framework could be used as a needs assessment to evaluate specific groups of students. Determining where there are significant differences between healthy and less healthy eaters would provide a guide to health educators in developing interventions based on the needs of the group of students they are working.

\section{Conclusion}

Explaining health behaviors decisions and understanding what influences them is essential to the development of effective interventions aimed at improving health though lifestyle choices. The current study assessed the descriptive Multi-Attribute Utility model's usefulness in predicting eating a healthy diet, namely, fruits and vegetables, and it provided preliminary support that the MAU model may be an appropriate framework to evaluate predictors of health behavior choices. Because the relationship found currently was small, subsequent studies using greater specificity in language on the MAU survey could provide stronger support for the use of MAU for predicting fruit and vegetable consumption.

With additional data collection, research and study, MAU assessments could be developed for a variety of health behaviors. It may be possible to develop expected outcome items for a variety of health behaviors for specific target groups, 
i.e., binge drinking and college students; distracted driving and adolescents, etc. Evaluation of the individual parameters of the MAU model (subjective value, subjective likelihood, momentary salience, product of consequences) could help guide health educators in designing health behavior interventions as it would shed light on which consequence has the greatest impact on behavior choice.
Consequences that prove to have high utility for a specific health behavior could be used as central focus in educational programs, social marking and other health intervention activities. Additionally, using the MAU model in the development of educational interventions will provide additional opportunity to evaluate its validity as a health behavior theory.

\section{References}

Avena, N., Rada, P., \& Hoebel, B. (2009). Evidence for sugar addiction: Behavioral and neurochemical effects of intermittent, excessive sugar intake. Neurosci Biobehav Rev, 32, 20-39.

American College Health Association (2009). National College Health Assessment II, Reference Group Data Report Fall 2008. Baltimore: American College Health Association.

American Diabetes Association (2009). How to prevent or delay diabetes. Available at: http://www.diabetes.org/food-nutrition-lifestyle/lifestyle-prevention/prevention/how-to-prevent-ordelay-diabetes.jsp. Accessed April 22, 2009.

American Heart Association (2009, April 20). Risk factors you can change. Available at: http://www.americanheart.org. Accessed April 22, 2009.

Blanchard, C., Fisher, J., Sparling, P. B., Shanks, T., Nehl, E., Rhodes, R.W., Baker, F., et al. (2009). Understanding adherence to 5 servings of fruits and vegetables per day: a theory of planned behavior perspective. Journal of Nutrition Education and Behavior, 41(1), 3-10.

Brownell, K. D. (2004). Fast food and obesity. Pediatrics, 113(1), 132.

Brug, J., Debie, S., van Assema, P. \& Weijts, W. (1995). Psychosocial determinants of fruit and vegetable consumption among adults: results of focus group interviews. Food Quality and Preference, 6, 99107.

Brunt, A.R., \& Yeong, S.R. (2008). Obesity and lifestyles in U.S. college students related to living arrangements. Appetite, 51, 615-621.

Center for Disease Control and Prevention (2005). Can eating fruits and vegetables help people to manage their weight? Available at:

http://www.cdc.gov/nccdphp/dnpa/nutrition/pdf/rtp_practitioner_10_07.pdf. Accessed August 7, 2012.

Delormier, T., Frohlich, K.L., \& Potvin, L. (2009). Food and eating as social practice - understanding eating patterns as social phenomena and implications for public health. Sociology of Health \& Illness, 31(2), 215-228.

Edwards, W. (1954). Behavioral decision theory. Annual Review of Psychology, 12, 473-498.

Flegal, K., Carroll, M. D., Kit, B. K., \& Ogden, C. L. (2012). Prevalence in obesity and trends in the distribution of body mass index among US adults, 1999-2010. JAMA, 307(5), 491-497.

Fromme, K., \& Dunn, M. E., (1992). Alcohol expectancies, social and environmental cues as determinants of drinking and perceived reinforcement. Addictive Behaviors, 17, 167-177.

Ha, E. J., \& Caine-Bish, N. (2009). Effect of nutrition intervention using a general nutrition course for promoting fruit and vegetable consumption among college students. Journal of Nutrition Education and Behavior, 41(2), $103-109$.

Hoffman, B. (2012). It's convenience, not cost, that makes us fat. Available at: http://www.forbes.com/sites/bethhoffman/2012/07/17/its-convenience-not-cost-that-makes-us-fat/. Accessed August 7, 2012.

Kandiah, J., Yake, M., Jones, J., \& Meyer, M. (2006). Stress influences appetite and comfort food preferences in college women. Nutrition Research, 26, 118-123.

Kandiah, J., Yake, M., \& Willett, H. (2008). Effects of stress on eating practices among adults. Family 
Hanlon, A.S., Weiss, J., McMahan, S., \& Cheng,. E. / Californian Journal of Health Promotion 2012, Volume 10, Special Issue:

Obesity Prevention and Intervention, 40-56

and consumer Sciences Research Journal, 37(1), 27-38.

Kasparek D. G., Corwin S.J., Valois R. F., Sargent R. G., \& Moris R. L. (2008). Selected health behaviors that influence college freshman weight change. J Am Coll Health. 2008;56:437-444.

Keeney, R. L., \& Raiffa, H. (1976). Decisions with multiple objectives. New York: Wiley.

Knutson, B.J. (2000). College students and fast food - how students perceive restaurant brands. Cornell Hotel and Restaurant Administration Quarterly, 41(3), 68 - 74.

Kushi, L. H., Byers, T., Doyle, C., Bandera, E. V., McCullough, M., Gansler, T., et al. (2006). American Cancer Society guidelines on nutrition and physical activity for cancer prevention: reducing the risk of cancer with healthy food choices and physical activity. CA Cancer Journal for Clinicians, 56, 254-281.

Larson N. I., Neumark-Sztainer D. R., Harnack L. J., Wall M. M., Story M. T., Eisenberg M.E. (2008). Fruit and vegetable intake correlates during the transition of young adulthood. Am J Prev Med. 35, $33-37$.

McMahon, J., \& Jones, B. T. (1994). Social drinkers' negative alcohol expectancy relates to their satisfaction with current consumption: Measuring motivation for change with the NAEQ. Alcohol and Alcoholism, 29, 687-690.

Mitchell, S. J. (1990). Changes after taking a basic college nutrition course. Journal of the American Dietetic Association, 90, 955-961.

Nishida, C., Uauy, R., Kumanyika, S. \& Shetty, P. (2004). The Joint WHO/FAO expert consultation on diet, nutrition and the prevention of chronic diseases: process, product and policy implications. Public Health Nutrition, 7(1a), 245-250.

Oliver, G., Wardel, J., \& Gibson, E. L., (2000). Stress and food choice: A laboratory study. Psychosomatic Medicine, 62, 853-865.

Park, C. L. (2004). Positive and negative consequences of alcohol consumption in college students. Addictive Behaviors, 29, 311-321.

Reid, M., Bunting, J., \& Hammersley, R. (2005). Relationships between the food expectancy questionnaire (FEQ) and the food frequency questionnaire (FFQ). Appetite, 45, 127-136.

Roininen, K., Lahteenmaki, L., \& Tuorila, H., (1999). Quantification of consumer attitudes to health and hedonic characteristics of food. Appetite, 33, 71-88.

Serlachius, A., Hamer, M., \& Wardle, J. (2007). Stress and weight change in university students in the United Kingdom. Physiology \& Behavior, 92(4), 548 - 553.

Shepard, R. N. (1964). On subjectively optimum selection among multiattribute alternatives. In M. W. Shelly \& G. L. Bryan (Eds.), Human judgments and optimality (pp. 257 - 281). New York: Wiley.

Smith, T. G. (2004). The McDonald's equilibrium: Advertising, empty calories, and the endogenous determination of dietary preferences. Social Choice and Welfare, 23, 383-413.

Tekol, Y. (2006). Salt addiction: A different kind of drug addiction. Med Hypotheses, 67, 1233-1234.

University of Tennessee, Chattanooga. (2011). Think \& achieve creating connections: Quality enhancement plan. University of Tennessee, Chattanooga. Available at: http://www.utc.edu/Administration/SACS/documents/FINAL_ThinkAchieve.pdf. Accessed May $25,2012$.

U.S. Department of Health and Human Services. (2010). The Surgeon General's Vision for a Healthy and Fit Nation. Available at: http://www.surgeongeneral.gov/library/obesityvision/ obesityvision2010.pdf. Accessed November 24, 2010.

U.S. Department of Agriculture. Dietary guidelines for Americans 2005. Available at: http://www.health.gov/DietaryGuidelines/default.htm. Accessed February 20, 2009.

Van Duyn, M.A., \& Pivonka, E. (2000). Overview of the health benefits of fruit and vegetable consumption for the dietetics professional: Selected literature. Journal of the American Dietetic Association, 100, 1511-1521.

von Winterfeldt, D., \& Edwards, W. (1986). Decision analysis and behavioral research. New York: Cambridge University Press.

Wall, A., Thrussell, C., \& Lalonde, R. N. (2003). Do alcohol expectancies become intoxicated outcomes? 
A test of social-learning theory in a naturalistic bar setting. Addictive Behaviors, 28, 1271-1283.

Wardle, J., Haase, A. M., Steptoe, A., Niilapun, M., Jonwutiwes, K., Bellisle, F. (2004). Gender differences in food choices: The contribution of health beliefs and dieting. Annuals of Behavioral Medicine, 27(2), $107-116$.

Weaver, M. R., Brittin, H. C. (2001). Food preferences of men and women by sensory evaluation versus questionnaire. Family and Consumer Science Research Journal, 29, 288-301.

Weiss, J. W., Edwards, W., \& Mouttapa, M. (2009). The puzzle of adolescent substance initiation. In Weiss, J.W., \& Weiss, D.J., (Eds.), A science of decision making: The legacy of Ward Edwards (pp. 439 - 450). New York: Oxford University Press.

Weiss, J. W., \& Edwards, W. (2009). Big decision, little decisions: The hierarchy of everyday life. In Weiss, J.W., \& Weiss, D.J., (Eds.), A science of decision making: The legacy of Ward Edwards (pp. 451 - 459). New York: Oxford University Press.

Weiss, J. W., \& Weiss, D. J., \& Edwards, W. (2010). A descriptive Multi-Attribute Utility model for everyday decisions. Theory and Decision. doi: 10.1007/s11238-009-9155-1

Weiss, J. W., \& Weiss, D. J., (2012). Irrational: At the moment. Synthese. doi: 10.1007/s11229-012$0112-0$

\author{
Author Information \\ *Anna Stiles Hanlon, MS, MPH \\ Orange Coast College \\ Kinesiology and Athletics \\ 2701 Fairview Road \\ Costa Mesa, CA 92626 \\ Email: ahanlon@cccd.edu \\ Jie Weiss, $\mathrm{PhD}$ \\ California State University, Fullerton \\ Department of Health Science
}

Shari McMahan, PhD

California State University, Fullerton

College of Health and Human Development

Emily Cheng, MA

California State University, Fullerton

Department of Psychology

* corresponding author 